\title{
LAA Closure: Where we stand now?
}

\author{
Yoga Yuniadi
}

I nsiden fibrilasi atrium diperkirakan akan makin meningkat dimasa yang akan datang. ${ }^{1}$ Stroke merupakan persoalan besar pada fibrilasi atrium dengan risiko hingga 5 kali lebih besar dibandingkan pasien tanpa fibrilasi atrium. ${ }^{2}$ Bahkan risiko stroke tersebut tidak berbeda baik pada fibrilasi atrium yang paroksismal maupun persisten. ${ }^{3,4}$ Terlebih lagi penderita fibrilasi atrium bila mengalami stroke umumnya mempunyai gejala yang lebih berat, disabilitas yang lebih parah serta rekurensi yang lebih sering dibandingkan pasien non fibrilasi atrium. ${ }^{5}$, ${ }^{6}$ Oleh karena itu stratifikasi risiko stroke pada pasien fibrilasi atrium menjadi sangat penting untuk pencegahan stroke yang lebih baik dan terarah. Skor CHA2DS2VaSc terbukti efektif sebagai panduan pemilihan pasien fibrilasi atrium yang mendapat terapi antikoagulan. ${ }^{7}$ Antikoagulan baik antagonis vitamin $\mathrm{K}$ (warfarin) maupun antikoagulan oral baru (direct antithrombin atau anti faktor $\mathrm{Xa}$ ) secara signifikan dapat menurunkan kejadian stroke dengan komplikasi perdarahan yang kecil..$^{8-11}$

Upaya pencegahan stroke pada fibrilasi atrium bukan hanya dilakukan melalui pemberian antikoagulan tetapi dilakukan juga secara mekanik dengan cara menutup apendiks atrium kiri (AAK). Rasional penutupan AAK karena AAK merupakan lokasi tersering (hingga 90\%) terbentuknya trombus yang kemudian lepas dan mengakibatkan emboli di otak. Oleh karena itu menutup AAK akan menurunkan

\section{Corresponding Address:}

Dr. dr. Yoga Yuniadi, SpJP, Divisi Aritmia, Departemen Kardiologi dan Kedokteran Vaskuler FKUI dan Pusat Jantung Nasional Harapan, Kita, JI S Parman Kav 87 Jakarta I I420, E-mail: yogayun@yahoo.com kejadian stroke sebagaimana diperlihatkan pada berbagai uji klinis. PROTECTion in patients with Atrial Fibrillation (PROTECT AF) suatu uji klinis 707 pasien AF memperlihatkan bahwa alat penutup AAK Watchman tidak inferior dibandingkan warfarin. ${ }^{12}$ Bahkan ketika observasi diteruskan hingga 4 tahun terlihat superioritas Watchman terhadap warfarin. ${ }^{13}$ Amplatzer Cardiac Plug (ACP) jenis penutup AAK yang lain memperlihatkan keberhasilan implantasi yang tinggi hingga 96\%. Sekalipun saat ini Watchman dalam tahap akhir persetujuan FDA tetapi karena masih terbatasnya bukti klinis tentang efikasi dan keamanan penutup AAK maka rekomendasi yang ada terbatas bagi pasien yang memiliki kontraindikasi pemakaian antikoagulan oral jangka panjang. ${ }^{7}$

Di Indonesia penutup AAK sudah mulai digunakan. Setidaknya tiga rumah sakit di Jakarta yaitu Pusat Jantung Nasional Harapan Kita, RS Bina Waluya dan RS Medistra telah memasang penutup AAK dari jenis yang berbeda-beda. Pengalaman penulis memakai ACP tidak terlalu sulit dipasang dengan learning curve yang cepat untuk angka keberhasilan pemasangan mencapai $100 \%$. Punksi transeptal harus di lokasi lebih ke inferior dari fosa ovalis, akan tetapi hal ini tidak jadi masalah karena transeptal dilakukan dengan panduan transesofageal ekokardiografi (TEE). Proctorship pada awal pemasangan penutup AAK perlu dilakukan agar terbiasa dengan alat baru ini dan untuk mencegah komplikasi yang tidak perlu. Biasanya diperlukan 6-10 kasus dengan proctorship sebelum dapat melakukan secara mandiri. Komunikasi dari ketiga rumah sakit pionir pemasangan penutup AAK di atas tidak ada laporan komplikasi fatal durante dan pasca pemasangan. 
Sebagai sebuah cara alternatif pencegahan stroke pada fibrilasi atrium, penutup AAK menjadi sebuah "new toys" yang sangat menarik terutama bagi kalangan elektrofisiologis dan intervensionis. Suatu tindakan yang memerlukan kompetensi khusus selalu menjadi tantangan yang ingin dicoba. Akan tetapi perlu diingat bahwa pencegahan stroke pada fibrilasi atrium perlu mempertimbangkan banyak faktor. Pencegahan stroke terbaik adalah dengan mengembalikan fibrilasi atrium menjadi irama sinus. Pada fibrilasi atrium terjadi stasis aliran darah di atrium kiri khususnya di AAK yang memudahkan terbentuknya trombus. Irama sinus akan menghilangkan stasis darah yang merupakan salah satu faktor trias Virchow pada proses koagulasi. Keberhasilan ablasi fibrilasi atrium dan mempertahankan irama sinus sangat dipengaruhi oleh dimensi atrium kiri yaitu dimensi atrium kiri yang kurang atau sama dengan $50 \mathrm{~mm}$ lebih menjamin pasien tetap irama sinus dalam jangka panjang. Oleh karena itu upaya kendali irama dengan ablasi isolasi vena pulmonalis seyogyanya menjadi pilihan pencegahan stroke pada fibrilasi atrium dengan dimensi atrium kiri yang tidak terlalu besar. Hal lain yang perlu dipertimbangkan adalah cost-effective. Obat-obat antikoagulan oral, baik antagonis vitamin $\mathrm{K}$ maupun direct thrombin inhibitor dan antagonis faktor $X$, menunjukkan hasil yang sangat baik dalam mencegah stroke. Oleh karena itu indikasi pemasangan penutup AAK masih dibatasi pada pasien yang memiliki kontraindikasi pemakaian antikoagulan oral jangka panjang. ${ }^{7}$

\section{Daftar Pustaka}

1. Miyasaka Y, Barnes ME, Gersh BJ, Cha SS, Bailey KR, Abhayaratna WP, Seward JB, Tsang TS. Secular trends in incidence of atrial fibrillation in Olmsted County, Minnesota, 1980 to 2000 , and implications on the projections for future prevalence. Circulation. 2006;114(2):119-125.

2. Savelieva I, Bajpai A, Camm AJ. Stroke in atrial fibrillation: update on pathophysiology, new antithrombotic therapies, and evolution of procedures and devices. Ann Med. 2007;39(5):371391.

3. Flaker GC, Belew K, Beckman K, Vidaillet H, Kron J, Safford R, Mickel M, Barrell P. Asymptomatic atrial fibrillation: demographic features and prognostic information from the Atrial Fibrillation Follow-up Investigation of Rhythm Management (AFFIRM) study. Am Heart J. 2005;149(4):657-663.

4. Hart RG, Pearce LA, Rothbart RM, McAnulty JH, Asinger RW, Halperin JL. Stroke with intermittent atrial fibrillation: incidence and predictors during aspirin therapy. Stroke Prevention in Atrial Fibrillation Investigators. J Am Coll Cardiol. 2000;35(1):183-187.

5. Lin HJ, Wolf PA, Kelly-Hayes M, Beiser AS, Kase CS, Benjamin EJ, D'Agostino RB. Stroke severity in atrial fibrillation. The Framingham Study. Stroke. 1996;27(10):1760-1764.

6. Penado S, Cano M, Acha O, Hernandez JL, Riancho JA. Atrial fibrillation as a risk factor for stroke recurrence. Am J Med. 2003;114(3):206-210.

7. Camm AJ, Lip GY, De Caterina R, Savelieva I, Atar D, Hohnloser SH, Hindricks G, Kirchhof P. 2012 focused update of the ESC Guidelines for the management of atrial fibrillation: an update of the 2010 ESC Guidelines for the management of atrial fibrillation. Developed with the special contribution of the European Heart Rhythm Association. Eur Heart J. 2012;33(21):2719-2747.

8. Morgan CL, McEwan P, Tukiendorf A, Robinson PA, Clemens A, Plumb JM. Warfarin treatment in patients with atrial fibrillation: observing outcomes associated with varying levels of INR control. Thromb Res. 2009;124(1):37-41.

9. Connolly SJ, Ezekowitz MD, Yusuf S, Eikelboom J, Oldgren J, Parekh A, Pogue J, Reilly PA, Themeles E, Varrone J, Wang S, Alings M, Xavier D, Zhu J, Diaz R, Lewis BS, Darius H, Diener $\mathrm{HC}$, Joyner CD, Wallentin L. Dabigatran versus warfarin in patients with atrial fibrillation. NEnglJ Med. 2009;361(12):11391151.

10. Granger CB, Alexander JH, McMurray JJ, Lopes RD, Hylek EM, Hanna M, Al-Khalidi HR, Ansell J, Atar D, Avezum A, Bahit MC, Diaz R, Easton JD, Ezekowitz JA, Flaker G, Garcia D, Geraldes M, Gersh BJ, Golitsyn S, Goto S, Hermosillo AG, Hohnloser SH, Horowitz J, Mohan P, Jansky P, Lewis BS, Lopez-Sendon JL, Pais P, Parkhomenko A, Verheugt FW, Zhu J, Wallentin L. Apixaban versus warfarin in patients with atrial fibrillation. N Engl J Med. 2011;365(11):981-992.

11. Patel MR, Mahaffey KW, Garg J, Pan G, Singer DE, Hacke W, Breithardt G, Halperin JL, Hankey GJ, Piccini JP, Becker RC, Nessel CC, Paolini JF, Berkowitz SD, Fox KA, Califf RM. Rivaroxaban versus warfarin in nonvalvular atrial fibrillation. $N$ Engl J Med. 2011;365(10):883-891.

12. Holmes DR, Reddy VY, Turi ZG, Doshi SK, Sievert H, Buchbinder M, Mullin CM, Sick P. Percutaneous closure of the left atrial appendage versus warfarin therapy for prevention of stroke in patients with atrial fibrillation: a randomised non-inferiority trial. Lancet. 2009;374(9689):534-542.

13. Reddy VY, Doshi SK, Sievert H, Buchbinder M, Neuzil P, Huber $\mathrm{K}$, Halperin JL, Holmes D. Percutaneous left atrial appendage closure for stroke prophylaxis in patients with atrial fibrillation: 2.3-Year Follow-up of the PROTECT AF (Watchman Left Atrial Appendage System for Embolic Protection in Patients with Atrial Fibrillation) Trial. Circulation. 2012;127(6):720-729. 